Derecho penal 
lus et Praxis, Revista de la Facultad de Derecho

N. ${ }^{4} 41,2010$

ISSN 1027-8168

pp. $193-215$

\section{¿Quién es el juez justo?}

\section{Efraín Vassallo Sambuceti}

No juzguéis, para que no seáis juzgados. Porque con el juicio con que juzgáis, seréis juzgados, y con la medida con que medís, os será medido.

Evangelio según San Mateo 7, 1-2

\section{Introducción}

En 12 Angry Men (1957), la excelente película de Sidney Lumet, el tímido e inseguro jurado n. ${ }^{\circ} 2^{1}$ explica de la siguiente manera las razones por las cuales decidió votar por la culpabilidad del acusado en un juicio de parricidio: "Es difícil ponerlo en palabras. Solo creo que es culpable. Pensé que era obvio desde el comienzo. Nadie probó que era inocente". Debe resaltarse que la sentencia condenatoria acarreaba, en el caso, la pena de muerte como consecuencia necesaria.

El razonamiento prejuicioso del jurado n. ${ }^{\circ} 2$ lo lleva a considerar que la regla para administrar justicia es la de presumir la culpabilidad del procesado. De hecho, al comienzo de la película, todos los miembros del jurado - con una sola excepción - toman la misma decisión, adoptada, en buena parte, por el hecho de que nadie en el proceso ha sido capaz de demostrarles que el acusado es inocente.

1 Interpretado por el actor John Fiedler. 
Esos jurados parten de una premisa obviamente equivocada, ya que tanto en su sistema judicial como en el nuestro, no solo la regla, sino la garantía constitucional, es que toda persona se presume inocente y debe ser reputada como tal hasta que no se declare judicialmente su culpabilidad.

Pero, valgan verdades, ya sea por ignorancia, exceso de prejuicio o defectos en el sistema, lo cierto es que, en la práctica, la presunción de culpabilidad parece muchas veces la regla que rige nuestros litigios. Y esto es, por supuesto, serio y delicado, pues se trata de la aplicación indebida de un principio repudiado por nuestro ordenamiento constitucional, para privar de su libertad a los justiciables.

La presunción de inocencia desaparece y el ciudadano que es denunciado por un delito se convierte en culpable y cargará con todos los estigmas de la culpabilidad penal, hasta que no sea capaz de que se declare judicialmente su inocencia. Y, lo que es más lamentable, incluso habiendo probado su inocencia, puede arrastrar el peso de los prejuicios que lo identifican como alguien que fue procesado por una imputación de carácter criminal.

Administrar justicia es una de las responsabilidades más difíciles que puede ejercer un individuo. Siendo el ser humano una criatura dinámica, sensible, compleja, influenciable y en permanente cambio y evolución, parece casi un imposible pretender que quien ejerce la alta investidura de juez no se vea afectado, en algún grado, por prejuicios y conflictos internos; ello, por supuesto, independientemente de la buena voluntad y empeño que deposite en su misión.

Lumet y Reginald Rose, el escritor de la obra, parecen comprender perfectamente esta realidad; de hecho, Rose basó la historia en su experiencia personal como jurado en un caso de homicidio involuntario. 12 Angry Men es un retrato perfecto de los diversos vicios y prejuicios que pueden afectar a un juzgador ${ }^{2}$ en el ejercicio de esta función, más allá de que sea consciente o no de dichos obstáculos a una justa decisión.

2 Los miembros del jurado en un caso criminal cumplen, como es obvio, una de las funciones del juez: concluir en la culpabilidad o inocencia del acusado. 


\section{Sinopsis de 12 Angry Men}

En un tribunal de justicia norteamericano, un joven de los barrios marginales es acusado de haber asesinado a su padre luego de una fuerte discusión. Las pruebas de su culpabilidad parecen ser lo suficientemente sólidas como para condenarlo: hay testigos, no

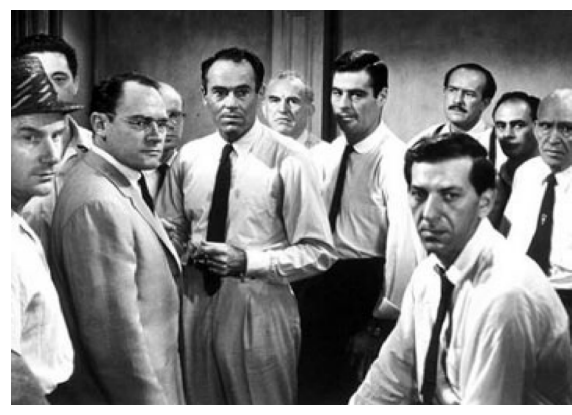
tiene una coartada creíble, es encontrado con un cuchillo que bien podría ser el que se usó para matar a la víctima, y, en el calor de la discusión, amenazó al padre con matarlo.

Un parco juez ${ }^{3}$ instruye al jurado, compuesto por doce desconocidos, ${ }^{4}$ sobre sus obligaciones. Les dice que si existe, en el curso de sus deliberaciones, alguna duda razonable sobre la culpabilidad del acusado, el veredicto deberá ser por la inocencia; en cambio, si el pronunciamiento es por la culpabilidad, la pena será de muerte y no aceptará - anticipa - ninguna petición de clemencia.

Los doce miembros del jurado ingresan a lo que será el único escenario del resto de la película: una calurosa, claustrofóbica y pequeña sala de deliberaciones. Luego de divagar durante algunos minutos, deciden cumplir el mandato que se les ha encomendado. El presidente del jurado ${ }^{5}$ los invita a sentarse en el mismo orden que ocuparon en el juicio. Ellos lo hacen. Uno de ellos sugiere votar directamente; la mayoría lo acepta; los otros callan. El presidente les pide que voten a mano alzada. Once levantan sus brazos, expresándose por la culpabilidad del acusado. Algunos lo hacen inmediatamente; otros, con cierta inseguridad, se toman uno o dos segundos. Solo uno vota por la inocencia: el reflexivo jurado n. ${ }^{\circ} 8 .^{6}$

La decisión del jurado n. ${ }^{\circ} 8$ genera reacciones adversas. Ya sea que se declare al acusado culpable o inocente, dicha decisión debe ser tomada

Interpretado por el actor Rudy Bond.

Existen dos jurados suplentes que no tienen relevancia en esta historia.

Interpretado por el actor Martin Balsam.

Interpretado por el actor Henry Fonda. 
por unanimidad y no por mayoría. "¿Usted cree en realidad que el muchacho es inocente?", le preguntan al jurado n. ${ }^{\circ}$ 8. "No lo sé. Solo creo que, tratándose de la vida de un ser humano, debemos tomarnos más tiempo para pensarlo", responde, refiriéndose a la condena a muerte que le correspondería al acusado si se le declarara culpable.

Las pruebas parecen ser lo suficientemente sólidas para varios miembros del jurado. Le increpan al jurado n. ${ }^{\circ} 8$ su decisión, se enojan con él y le piden que los convenza. Luego de deliberar y discutir amargamente durante algunos minutos, el jurado n. ${ }^{\circ} 8$ les propone: "Voten ustedes, yo me abstendré. Háganlo en secreto. Si la votación por la culpabilidad es unánime, yo me uniré a esa decisión. Si hay uno solo que vota por la inocencia, seguiremos deliberando". Ellos aceptan y votan en secreto. Se hace el escrutinio y se descubre que un miembro más del jurado se inclina por apoyar la tesis de la inocencia.

La reacción de aquellos miembros del jurado que parecen estar convencidos de la culpabilidad del joven acusado es de furibunda indignación; y, más allá de ese aparente convencimiento, la frustración hace que afloren los verdaderos motivos - quizá inconscientes - que los llevan a querer que el acusado sea ejecutado por su supuesto parricidio. El irascible jurado $n .^{\circ} 3^{7}$ ve en el joven acusado el reflejo de su propio hijo, con quien ha tenido una relación tormentosa que lo llevó a ser víctima de una agresión física por parte de éste. El adusto jurado $n .{ }^{\circ} 4^{8}$ parece tener una estructura mental fría e impenetrable, poco dispuesta a la reflexión y a la apertura de nuevos argumentos. El irresponsable jurado $n .{ }^{\circ} 7^{9}$ está más interesado en concurrir, como espectador, al partido de fútbol americano que se jugará horas más tarde, por lo que insiste en que la decisión de culpabilidad se tome cuanto antes y sin perder el tiempo con innecesarias deliberaciones. Finalmente, el ignorante jurado n. ${ }^{0} 10^{10}$ recurre a todo tipo de prejuicios y expresiones clasistas y racistas para justificar que el joven acusado, de rasgos no caucásicos y de un barrio

Interpretado por el actor Lee J. Cobb.

Interpretado por el actor E.G. Marshall.

Interpretado por el actor Jack Warden.

Interpretado por el actor Ed Begley. 
marginal, sea condenado. El resto de los miembros del jurado presenta posiciones variadas, revelando manifestaciones de inseguridad, aburrimiento, respeto y reflexión por la misión que desempeñan.

Basta con lo escrito para interesar al lector en el visionado de un filme que tiene una riqueza filosófico-jurídica impresionante y que me obliga a formular el siguiente cuestionamiento: ¿está en realidad el ser humano preparado para juzgar correctamente?

\section{La acción de juzgar como característica humana}

La pregunta que acabo de formular parece tener, a primera impresión, una respuesta sencilla. Más allá de que el ser humano esté o no preparado para juzgar correctamente, lo cierto es que la acción de juzgar es consustancial a su naturaleza.

En efecto, científicos de la Universidad de Yale han descubierto que el ser humano es capaz de juzgar a los demás desde su primer año de vida, siendo, por ello, los infantes, capaces de distinguir entre amigos y enemigos. ${ }^{11}$

La investigación - que también fue publicada el 2007 por la revista británica Nature - reveló que los niños de esa edad ya pueden distinguir al resto de seres humanos entre atractivos y repulsivos, según los comportamientos individuales que estos hayan mostrado con los demás. Los científicos añaden que los niños prefieren la compañía de aquellas personas que no se muestran como un obstáculo para las otras y que, por el contrario, ayudan al resto con sus problemas y dificultades. En esa misma línea, concluyen que esta capacidad puede sentar las bases del pensamiento y del sentido moral del individuo.

Ahora bien, es sobre la base de esta sensiblemente viva capacidad para juzgar, que pueden surgir los prejuicios en el ser humano. El niño, por supuesto, no nace con prejuicios contra las personas de otra raza,

${ }^{11}$ Gaceta Yale-México. Primavera del 2008, volumen 3, n. ${ }^{\circ}$ 1. México, p. 5. El estudio fue realizado por el Departamento de Psicología de la Universidad de Yale en bebés de entre seis y diez meses de vida. 
origen, credo, orientación sexual, sexo o aspecto físico; sin embargo, sí puede hacerse consciente de algunas de estas diferencias desde una temprana edad. Pues bien, al cobrar conciencia de estas diferencias, puede asumir rechazos, de diverso grado, en la medida en que sea expuesto a prejuicios modelados por otras personas, respecto de las que tiene confianza o admiración. Así surgirán los prejuicios en ese niño.

Estos prejuicios pueden verse reforzados o alimentados por las relaciones que asume el niño en el desarrollo de su crecimiento. Así, si el niño caucásico aprende a menospreciar a los de rasgos indígenas porque escuchó a su padre maltratar a una persona con estos rasgos y a propósito de ellos, reforzará ese aprendizaje si al llegar al colegio escucha que sus compañeros hacen comentarios despectivos de los indígenas.

Pero eso no es todo; el inconsciente del ser humano puede hacerlo víctima de prejuicios y aversiones a ciertos grupos sociales o comportamientos, en la medida en que se ha visto afectado por experiencias personales o cercanas. Una mujer, por ejemplo, que ha sufrido en su niñez la dolorosa prueba de haber visto a su madre ser víctima de abusos físicos por parte de su padre, puede sentirse condicionada a favorecer la posición de la mujer en una relación sentimental tormentosa en la que ambas partes alegan tener la razón. Un hombre que en su adolescencia vio cómo a su endeudado padre el banco le embargaba y ejecutaba la casa, echándolo a él y a toda su familia a la calle, puede tener un sentimiento de rechazo contra la figura fría e institucional de una entidad bancaria.

La acción de juzgar es, en consecuencia, propia de la naturaleza humana. Se juzga desde la infancia, sobre la base de lo que se percibe, y a partir de allí se continúa juzgando durante todo el proceso del desarrollo humano. Desde que existen valores inculcados por la familia, la escuela, la religión, la comunidad y el Estado, el ser humano no puede evitar emitir juicios, aunque estos solo sean recibidos - o percibidospor su fuero interno.

Pero no hay que perder en cuenta que el prejuicio es también característico de la naturaleza humana. La complejidad de la sensibilidad del individuo lo hace susceptible a los modelos negativos transmitidos por terceros, así como a las experiencias vividas.

Es sobre la base de aquella característica humana - la de juzgar-, ante la ocurrencia de conflictos, que la sociedad encarga a individuos, 
supuestamente preparados y calificados, emitir juicios que permitan la resolución de estos conflictos. Repito: la disposición del ser humano a juzgar es propia de su naturaleza, por lo que recibir ese encargo parece ser algo absolutamente razonable; de hecho, otro camino no puede existir, ya que, de otra forma, ¿cómo podrían resolverse los conflictos humanos que no dan tregua a una conciliación sincera entre las partes?

Sobre el particular, en la excelente obra Lecciones de derecho natural o filosofía del derecho, ${ }^{12}$ escrita a mediados del siglo XIX, el reconocido jurisconsulto y filósofo alemán Heinrich Ahrens nos dice, con mucha lucidez:

... la facultad de concebir lo verdadero, lo bueno y lo justo, ideas que expresan relaciones generales de los hombres entre sí, y con los seres y objetos del universo, es una facultad originaria, no derivada, innata, como se dice, y es un carácter distintivo de la naturaleza humana (...). Existe, pues, en el hombre una facultad general de juzgar lo que es justo, y de esta facultad primitiva resulta la noción general del Derecho, noción que es tan originaria en el hombre, como la facultad de donde se deriva, pero que necesita para ser completa, que se la desenvuelva por un trabajo intelectual, metódico.

La visión de Ahrens parte de un hecho real y necesario: la naturaleza humana permite, al hombre y a la mujer, juzgar. Ahrens es optimista y va más allá: el individuo también tiene la capacidad o la facultad de juzgar lo que es justo. En este concepto es donde debemos detenernos, ya que una cosa es juzgar y otra, muy diferente, es hacerlo con justicia. En este punto, nos volvemos a preguntar: ¿está capacitado el ser humano para juzgar correctamente, es decir, para hacerlo con justicia?

12 AHRENS, Heinrich. Curso de derecho natural ó filosofía del derecho formado con arreglo al estado de esta ciencia en Alemania. Traducido y aumentado con notas y una tabla analítica de materias por orden alfabético por don Ruperto Navarro Zamorano, abogado del Ilustre Colegio de Madrid. Madrid: Boix Editor, 1841, p. 38 . 
El problema es que esa natural disposición a juzgar y esa necesidad de que existan jueces encargados de resolver los múltiples conflictos humanos pueden verse contaminadas con la, también natural, tendencia a prejuzgar. Vale decir, el noble oficio de emitir un juicio objetivo, sobre la base de las diferentes pruebas que son presentadas por las partes de un conflicto, puede que no resulte siendo otra cosa que una simple ilusión, superada y aplastada por la cruda realidad que nos demuestra que el individuo tiende a prejuzgar. En otras palabras, lo verdaderamente natural podría terminar siendo el anticipar los juicios de valor, sobre la base de las simpatías o antipatías que los hechos o las partes involucradas en el conflicto nos generan.

Para juzgar con corrección o para juzgar con justicia, se esperan muchas cualidades del individuo. Imparcialidad, objetividad, honestidad, honradez intelectual, inteligencia, conocimientos jurídicos superiores, tolerancia y rectitud, son algunas de ellas. Sin embargo, estimo que la primera cualidad a la que debe aspirar un juez justo es la valentía. Con ella, cualquiera de las otras virtudes puede desarrollarse y aplicarse adecuadamente; sin ella, es probable que ninguna de las cualidades mencionadas - sin perjuicio de que se las tenga - sea útil al juez y a los justiciables que están en manos de este.

\section{La valentía de juzgar con rectitud y criterio de conciencia}

Cuando comienza el filme 12 Angry Men, el "justo" jurado n. ${ }^{\circ} 8$ parece más una máquina que un ser humano que asume la responsabilidad de decidir sobre la vida o la muerte de otro. Creo, sin embargo, que la interpretación que hace Henry Fonda es notable porque refleja mucho de lo que aquí se viene afirmando: habría que dejar de pensar como un ser humano para no tener la sensibilidad suficiente de inclinarse a pensar que el joven acusado no es culpable de haber matado a su padre.

Todas las pruebas parecen condenarlo, pero el jurado $n .{ }^{\circ} 8$ vota por su inocencia. Lo hace con gesto adusto y tranquilo. No se asusta y no duda. Es valiente. Está votando en contra de la decisión de once compañeros jurados, y lo hace con suma tranquilidad. Ello es inusual en la naturaleza humana; lo ordinario, lo común y lo más cómodo es seguir la tendencia de la mayoría, incluso - o más aún - si se trata de decidir sobre la responsabilidad penal de alguien. 
El anciano jurado n. ${ }^{\circ} 9^{13}$ admira su valentía: “Este caballero sustenta firmemente su posición contra la nuestra (...) no es fácil defender una opinión singular y someterse al ridículo que le hace el resto". Las intenciones del anciano jurado son las de calmar los ánimos, pero consigue todo lo contrario respecto de algunos de los miembros del jurado: comienzan los insultos, se exponen los prejuicios más absurdos, y las voces comienzan a alzarse con indignación.

El "justo" jurado n. 8 es el principal objeto de ataque de sus inconformes compañeros. Él mantiene su tranquilidad; no se sobresalta, no se molesta, no contesta los insultos. ¿Es realmente un ser humano o una máquina? Insiste en la inocencia, no porque esté convencido de ella, sino porque no está convencido de lo contrario y sabe perfectamente que en esos casos corresponde votar por la no culpabilidad del acusado.

No se alegra de ser la voz disonante del grupo, pero no está dispuesto a retroceder en su posición. Se reconoce como uno de los responsables de tomar una decisión que puede costarle la vida al acusado, y asume esa responsabilidad con valentía. "No es fácil levantar mi mano y mandar a la muerte a un muchacho sin antes hablar sobre ello", les dice. Confronta al resto con la convicción de que está obrando correctamente y conforme a los dictados de su conciencia.

He ahí la clave de la imparcialidad que debe caracterizar a cualquier juez justo: no existe posibilidad alguna de ser imparcial si no se tiene y se practica la virtud de la valentía. En efecto, como es obvio, el cobarde teme a las consecuencias de la defensa de sus criterios, siente miedo de exponer los dictados de su conciencia y aplicarlos correcta y honestamente.

Así, un juez cobarde no puede ser imparcial porque tolera cualquier tipo de presiones que conspiran contra su pretendida imparcialidad. Las presiones políticas lo atemorizan, las presiones mediáticas lo aterrorizan, las presiones económicas lo inquietan y seducen. Incluso, las amenazas y prepotencia de las partes y de sus abogados pueden llevarlo a tomar una decisión equivocada o contraria a sus principios.

${ }_{13}$ Interpretado por el actor Joseph Sweeney. 
Una triste y clara exhibición de la cobardía que puede caracterizar a un juez, hasta el punto de neutralizar su pretendida imparcialidad y nublar su conciencia, es la del impacto que en muchas ocasiones tienen los criterios de la mayoría. En un sistema judicial como el nuestro, en el que no existen jurados, podría ser difícil identificar ello en los niveles correspondientes a la primera instancia; sin embargo, no debemos perder de vista que existen otras instancias en las que la toma de la decisión depende de tres o hasta siete vocales. ${ }^{14}$

Esto se aprecia en 12 Angry Men con mucha claridad. Cuando se hace la primera votación para determinar si el adolescente acusado es culpable o inocente, seis de los miembros del jurado votan en forma inmediata, convencidos de que su decisión por la culpabilidad es la justa: se trata de los jurados n. ${ }^{\circ} 1$ (el presidente), n. ${ }^{\circ} 3$, n. $^{\circ} 4, n .{ }^{\circ} 7$, n. ${ }^{\circ} 10$ y n. ${ }^{\circ} 12 .{ }^{15}$ A continuación lo hace el jurado n. ${ }^{\circ}$; luego - evidenciando menos convencimiento- los jurados n. ${ }^{\circ}{ }^{16}$ y n. ${ }^{\circ} 6 .{ }^{17}$ Mirando el voto de sus compañeros - se deduce que como consecuencia de ello-, el jurado n. ${ }^{\circ} 11^{18}$ levanta el brazo con mucha lentitud. Finalmente, el anciano jurado n. ${ }^{\circ} 9$ se anima a votar, con mucha inseguridad, por la culpabilidad del acusado. El jurado n. ${ }^{\circ}$ 8, como ya se explicó, no levanta la mano porque defiende la posible inocencia del acusado.

Solo la genialidad de un gran director como Sidney Lumet puede reflejar, con pocas palabras, pero con mucha intensidad, un elemento presente y latente en varios de los miembros del jurado: la absoluta falta de valentía para expresar lo que piensan. Ellos se ven envueltos por sus dudas y suman a ellas el convencimiento y la decisión que tienen sus compañeros del jurado. Poco a poco, se sienten comprometidos con la decisión del resto y optan por la cómoda posición de sumarse a la mayoría.

La escena tiene una riqueza cinematográfica impresionante, que no puede ser explicada con palabras. Sin embargo, lo intentaré. El último

\footnotetext{
14 Este último caso es el del Tribunal Constitucional.

15 Interpretado por el actor Robert Webber.

${ }_{16}$ Interpretado por el actor Jack Klugman.

17 Intepretado por el actor Ed Binns.

18 Interpretado por el actor George Voskovek.
} 
voto a favor de la culpabilidad, el del anciano jurado n. ${ }^{\circ}$ 9, es el más gráfico y representativo de lo que se ha venido afirmando con relación a la valentía. Hay un gran trabajo de precisión narrativa del director. El espectador no ve el rostro del anciano; solo su delgada figura y su posición expectante de la decisión de la mayoría. Poco a poco, todos los miembros del jurado han votado por la culpabilidad. Solo han dejado de levantar la mano él y el compañero sentado a su costado derecho, el jurado n. ${ }^{\circ}$. El anciano no ve la decisión de este; su cabeza gira hacia la izquierda. Siente que no tiene más remedio que sumarse a lo que percibe como real: "Todos creen que es culpable". Levanta su brazo, pero lo hace con mucha duda. Es casi imperceptible, pero muy conmovedor, ver cómo intenta cambiar de opinión y bajar el brazo. Por una fracción de segundo, trata de defender la tesis de la inocencia. Sin embargo, su temor de enfrentar a la mayoría puede más. El anciano suma el undécimo voto a favor de la condena. Cuando el presidente cuenta en voz alta los votos, el más sorprendido de todos, por la decisión del jurado n. $^{\circ} 8$ de votar por la inocencia, es, precisamente, el inseguro y temeroso anciano.

El personaje del jurado n. ${ }^{\circ} 8$ se descubre entonces como el verdadero valiente de la película. No porque aquellos que votaron convencidos de la culpabilidad no hayan tenido esta virtud, sino porque aquel actuó con convicción, enfrentándose a la mayoría y siguiendo los dictados de su conciencia. El jurado n. ${ }^{\circ} 8$ no es, en consecuencia, la máquina que parece ser; se trata de un ser humano con la suficiente sensibilidad como para entender que una decisión tan importante, como es la de la determinación de una responsabilidad de carácter criminal, no puede depender de prejuicios y simples pareceres o primeras impresiones.

Es a partir de allí que puede conocerse otra de las virtudes del juez justo y que también se encuentra presente en el jurado n. ${ }^{\circ}$ 8: la responsabilidad y el empeño por la labor encomendada.

\section{La responsabilidad y el empeño de juzgar con rectitud y con criterio de conciencia}

"Votemos. Luego quizá podamos irnos de aquí, dice el jurado n. ${ }^{\circ} 7$, después de mirar su reloj. Al verlo, una lúcida sensación de desprecio aflora. Se trata del típico individuo que no le da ninguna importancia a sus responsabilidades. 
Decidir la suerte del adolescente no es más importante que asistir a su partido; ni siquiera se avergüenza de admitirlo. Él quiere terminar rápido y no le interesa si para ello debe sumarse a una posición o a otra. Casi pareciera que no se siente responsable de lo que ocurra con el muchacho y creyera que la decisión solo corresponde a los otros once miembros del jurado.

Cuando ve que las cosas se complican y que su asistencia al partido peligra, formula un reclamo: " ¿Nos quedaremos toda la noche discutiendo?". Uno de los miembros del jurado apunta: "Es solo una noche. ¡Un muchacho puede morir!”. Él bromea: “¿Por qué no acampamos aquí? Que alguien envíe al agente a buscar un juego de naipes y nos quedaremos a decidir todo". Más adelante, cuando el jurado n. ${ }^{\circ} 6$ sugiere votar de nuevo, él contesta: "Oh, genial. Quizá podamos continuar con un poco de baile y refrescos".

La displicencia del jurado $n .{ }^{\circ} 7$ me hace recordar a la del juez que en el filme conduce el proceso: parece un hombre aburrido y cansado de lo que hace; si no fuera una imagen relativamente común, podría pensarse que se trata de alguien enfermo. Tiene la cara brillante por el sudor, apoya el lado derecho de ella sobre una de sus manos y habla con agotamiento. Habla mucho, pero dice poco. Repite casi de memoria las instrucciones al jurado. No siente ningún compromiso con el joven acusado de parricidio que se encuentra frente a él.

Definitivamente, uno de los peores venenos que puede consumir quien administra justicia es el de la displicencia. El ser juez, el tener la responsabilidad de decidir respecto de la vida, ${ }^{19}$ la libertad o el patrimonio de los justiciables exige la capacidad de involucrarse en el conflicto. No para parcializarse con una de las partes, sino para tomar la decisión adecuada con el fin de resolver el conflicto a favor de una, de la otra, de ambas o de ninguna.

Involucrarse en el conflicto supone no solo aceptar entenderlo, sino estar dispuesto a conocerlo en profundidad, comprenderlo en forma

19 Aunque en el Perú la pena de muerte es excepcional y prácticamente inaplicable, no podemos dejar de considerar esta posibilidad en la reflexión sobre las potestades y responsabilidades que tiene un juzgador. 
plena y asumirlo con inteligencia y ponderación. El juez justo no conoce un caso sólo porque es su obligación. Ama su trabajo y se entusiasma con la posibilidad de aplicarlo con empeño y rectitud. Crece profesionalmente con los casos difíciles y crece como individuo, aplicando justicia con verdadero criterio de conciencia.

La displicencia en un juez neutraliza el criterio de conciencia y deja un vacío muy grande; en ese espacio vacío es donde suelen actuar los prejuicios. El juez displicente se torna huraño. Su trabajo le molesta, sus auxiliares le incomodan, los abogados le irritan y las partes del litigio son un fastidio, un problema y un obstáculo. Ante una situación como esa, cualquier experiencia negativa, conflicto interno o desprecio que el juez tenga por alguna de las partes, o por el grupo al que pertenece o al que está vinculada ella, puede inclinar la balanza al momento de tomar su decisión.

Ahora bien, la displicencia de un juez no se presenta solo por el interés de este en asistir a un partido de fútbol americano, o de fútbol soccer, o por querer regresar temprano a su casa y estar con su familia, o por querer participar de una actividad privada. Afirmar eso sería como sostener que la displicencia y la falta de empeño son atribuibles única y exclusivamente a la persona del juez, lo que constituiría una burda simplificación del problema, que no nos permitiría encontrar solución alguna.

Lo cierto es que un sistema procesal en el que no existen las mínimas condiciones de seguridad, comodidad y logística, agota y desanima a cualquier administrador de justicia. Si cada juez es encargado de "conocer" más de mil quinientos expedientes, es evidente que tiene que tratar $-\mathrm{o}$, más bien, lidiar - con más de tres millares de personas y sus abogados. Los pedidos, reclamos, recusaciones, amenazas, denuncias, quejas funcionales y hasta insultos, pueden convertir a un juez que aspiró a ser "justo", en el enemigo de sus propios justiciables.

Por supuesto, estas últimas reflexiones no se aplican al irresponsable jurado n. ${ }^{\circ}$, ya que él estuvo "involucrado" en el conocimiento del caso sólo unos cuantos días. Se sabe que esto también es frecuente, por lo que no se puede dejar de considerar la común responsabilidad que, en materia de falta de empeño en la asunción de sus obligaciones jurisdiccionales, tienen tanto la sociedad y el Estado, como los propios jueces.

Considero que, desde una perspectiva estrictamente psicológica, el problema pasa por un déficit en la autoestima. El juez no llega a ser cons- 
ciente de lo verdaderamente trascendental que puede ser su función, y esto puede deberse también al desprecio o poca confianza que la población tiene en ella. En otras palabras: se genera un círculo vicioso que no da tregua. El juez no logra superar, en el entorno de sus justiciables, la imagen de incómodo entrometido que sabe poco del conflicto y que no tiene disposición alguna para resolverlo correctamente. La desconfianza genera más desconfianza, y el daño a la autoestima es casi una consecuencia obligatoria: si los justiciables no respetan el trabajo de quien puede, debe y está obligado a resolver su problema, es natural que esa misma persona, el juzgador, estime que lo que hace carece de importancia.

Sobre el particular, es destacada la visión que tiene el profesor de la Universidad de Stanford, John Henry Merryman. El ilustre comparatista estadounidense refiere que en la tradición jurídica romano-canónica, la imagen neta del juez es la del

... operador de una máquina diseñada y construida por los legisladores. Su función es meramente mecánica. Los grandes nombres del derecho civill${ }^{20}$ no son los de los jueces (¿quién conoce el nombre de un juez del derecho civil?), sino los de legisladores (Justiniano, Napoleón) y académicos (Gayo, Irnerio, Bartolo, Mancini, Domat, Potier, Savigny y una multitud de académicos europeos y latinoamericanos de los siglos XIX y XX). El juez del derecho civil no es un héroe cultural ni una figura paternal, como lo es frecuentemente entre nosotros. ${ }^{21} \mathrm{Su}$ imagen es la de un empleado público que desempeña funciones importantes, pero que resultan esencialmente poco creativas. ${ }^{22}$

Posición fundamental, que se suma a la antes expuesta para explicar el problema en la autoestima de los juzgadores. Merryman considera que nuestra tradición desmotiva la natural función creativa del juez y lo convierte en un mero operario de normas estáticas. "El servicio judicial es una

20 Se refiere a la tradición jurídica romano-canónica.

${ }^{21}$ Se refiere a la tradición anglosajona.

22 MERRYMAN, John Henry. La tradición jurídica romano-canónica. México D.F.: Fondo de Cultura Económica, 1997, p. 77. 
carrera burocrática; el juez es un funcionario, un empleado público; la función judicial es estrecha, mecánica y nada creativa". ${ }^{23}$ Por otro lado, en lo que Merryman denomina derecho común - vale decir, en la tradición anglosajona-, el juez es una figura paternal, querida y respetada, que crea y modela derecho, y la función legislativa es complementaria a la judicial.

Claro está, el filme 12 Angry Men está basado en la tradición anglosajona, y aún así vemos la figura de un juez gris, parco, huraño y apagado. Sin embargo, la comparación de Merryman no defiende la infalibilidad intelectual y mental de los jueces anglosajones, pero sí es válida para comprender cómo, en un sistema más mecánico - como el nuestro-, el juez está más expuesto a sufrir una seria exposición en su autoestima, por la forma en que tiene que desempeñar su función.

Diferente, por supuesto, es la posición del jurado n. ${ }^{\circ}$ 8: él sí asume con empeño, responsabilidad y seriedad su función de decidir si el acusado es culpable o inocente. El desempeño de dicha función está por encima del tiempo que pueda tomarle y de la incomodidad que pueda generar su singular voto en el resto de los miembros del jurado.

Levantar la autoestima de los jueces ${ }^{24}$ es un trabajo de los especialistas. Concurrirán en dicha misión no solo psicólogos, abogados y ex magistrados, sino también profesionales en coaching y recursos humanos. Sin embargo, no debe confundirse la importante tarea de elevar la autoestima con la conversión del juez en un personaje prepotente y con delirios de grandeza. El juez debe ser objetivo y tolerante en su labor y no ceder a la tentación de la vanidad y de la obcecación.

\section{La tolerancia y objetividad de juzgar con rectitud y criterio de conciencia}

Viendo 12 Angry Men, no podemos dejar de sentirnos interesados por la figura del jurado n. ${ }^{\circ}$ : un hombre maduro, de rostro circunspecto, de mirada adusta y sin ánimo de sociabilizar con ninguno de sus compa-

${ }^{23} \quad$ Ibíd., p. 79.

${ }^{24}$ Evidentemente, no pretendo generalizar en esta nota; me refiero sólo a los casos en los que se produce el vicio antes descrito. 
ñeros. ${ }^{25}$ Está convencido de la culpabilidad del joven acusado y expresa sus opiniones con mucha seguridad y lucidez; su hablar es pausado y respetuoso, y su razonamiento, metódico.

Sin embargo, hay algo oscuro en dicho personaje: parece la imagen viva de la frialdad. Está perfectamente peinado y afeitado, mientras que el resto de los miembros del jurado andan desaliñados por la intensa y larga discusión. Lleva un elegante terno, del que no se desviste en ningún momento, a diferencia de los otros personajes, y no se siente afectado en lo absoluto por el insoportable calor que agobia a todos. Cuando un empapado por el sudor jurado $n$. $^{\circ} 5$ le pregunta si nunca transpira, responde en forma cortante: "No, nunca".

El jurado n. ${ }^{\circ} 4$ es un típico hombre obcecado. Está dispuesto a razonar sólo con relación a sus propios parámetros, que lo llevan a considerar que los hechos expuestos en el juicio son lo suficientemente claros como para votar por la condena del joven acusado. No está interesado en conocer las profundidades psicológicas del muchacho, tampoco quiere mirar en la interioridad de la difícil relación que existía entre padre e hijo, y mucho menos se atreve a evaluar la posibilidad de que los testigos del crimen se hayan equivocado o tengan razones personales para exagerar o falsear su testimonio.

Desgraciada es la suerte de un inculpado que cae en manos de un juez que cree en su culpabilidad desde el comienzo del proceso. La obcecación de un juez es un grave vicio que destruye la posibilidad de un juicio justo, porque ciega y obnubila al juzgador, hasta el punto de permitir que sus prejuicios, odios y rencores dominen y sometan su capacidad de evaluar con objetividad los hechos y las personas que está juzgando.

Es cierto que se puede llegar a la obcecación por la vía de los prejuicios, pero también - tanto o más grave que eso- por la perversa seducción que da la ilusión del ejercicio del poder. Quien tiene en sus manos la decisión de la vida, la libertad o la propiedad de un tercero, puede sentirse seducido con ese poder y obcecarse en su uso, hasta el punto de

25 Resulta impactante la escena en la que el jurado n. ${ }^{\circ}$, prácticamente, no mira la tarjeta de presentación que con amabilidad le muestra su compañero de al lado, el jurado $n .^{\circ} 3$. 
querer presentarse ante la sociedad, más como un implacable justiciero que como un justo juez.

Severidad ciega y rigor obnubilado son los ingredientes principales de la obcecación de un juez convertido en justiciero. Podría pensarse que este vicio - el de la obcecación - es excluyente del analizado en el punto anterior - el de la autoestima herida -; sin embargo, yo creo que son perfectamente complementarios. En efecto, un juez herido en su autoestima - como consecuencia de las falencias que hemos comentado líneas arriba-, puede encontrar en la obcecación justiciera un mecanismo de compensación de sus vacíos o insatisfacciones.

El juez obcecado suele no ver más allá de los hechos. Se propone no hacerlo. En ocasiones, expresa ese propósito con orgullo, cuando en el ánimo de la defensa se presentan argumentos vinculados a la persona del acusado, más allá de los hechos que se le imputan. Esta obcecación por sólo conocer los hechos fue considerada como escandalosa por el maestro Francesco Carnelutti, quien en su clásico Las miserias del proceso penal ${ }^{26}$ nos señalaría: "No se ha de creer que el ambiente de los juristas haya permanecido insensible a este escándalo. Hace ya mucho tiempo que los juristas se han dado cuenta de que para el juicio penal es necesario, además de conocer el hecho, conocer al hombre; y conocer al hombre no es posible sin reconstruir su historia".

Es cierto que los juristas pueden haberse conducido bajo dichos criterios desde hace ya varios años; de hecho, ello explica por qué en el Código de Procedimientos Penales peruano de 1940 se prevé la posibilidad de que el inculpado ofrezca testigos de probidad y buena conducta. ${ }^{27}$ El problema se da en la aplicación de estos criterios en el nivel correspondiente a quienes tienen la responsabilidad de decidir sobre la culpabilidad o inocencia de un individuo en el proceso penal.

CARNELUTTI, Francesco. Las miserias del proceso penal. Lima: Temis, 1999, p. 58. Ello está establecido así en el artículo 138 del referido código, el que se encuentra vigente en diversos distritos judiciales del país. Es evidente que los testigos de probidad y de conducta no tienen ninguna vinculación con los hechos supuestamente delictivos que se investigan, pero sí con la persona del inculpado. 
Después de todo, como hemos referido, la ceguera y obnubilación son características de la obcecación, por lo que no debiera llamar la atención que un juez obcecado no entienda las razones que le obligan a interesarse por la persona del acusado y por su historia personal, para poder dar un veredicto justo.

Ello es finalmente lo que ocurre con el jurado n. ${ }^{\circ} 4$, quien se niega a ver más allá de los hechos que le fueron expuestos en el juicio y no admite considerar que la génesis de la aparente culpabilidad del acusado se encuentra en una mala defensa de su abogado, quien ni siquiera tuvo la audacia de interrogar correctamente a los testigos.

Por supuesto, la obcecación no afecta sólo al jurado n. ${ }^{\circ} 4$. De hecho, aunque obcecado, por lo menos él sí está dispuesto a discutir con respeto y altura, sin recurrir a insultos o agresiones. Apunto esto porque no puedo pasar por alto en este análisis la figura de los dos protagonistas más representativos de la necedad de 12 Angry Men: me refiero a los jurados n. ${ }^{\circ} 3$ y n. ${ }^{\circ} 10$.

Ver la forma tan obsesionada en que postulan la necesidad de que el joven acusado sea condenado y se le aplique la pena de muerte, causa zozobra e indignación. ¿Sienten realmente que están aplicando justicia? $¿ \mathrm{O}$ es que acaso encuentran en el castigo al joven acusado un escape a sus propios problemas y traumas personales?

El jurado n. 3 es de reacciones coléricas y tosco en sus formas. No soporta que lo contradigan y alza la voz cada vez que siente que no lo escuchan. Detesta que el jurado n. ${ }^{\circ} 8$ haya asumido el liderazgo del debate en sustitución del presidente y está dispuesto a llegar a la agresión física para hacer prevalecer su posición. Al igual que el jurado n. ${ }^{\circ}$ 4 , se trata de un hombre obcecado, pero suma a esa obcecación una clara perturbación mental, sumergida en su inconsciente y que no le permite considerar la inocencia del joven acusado, a quien ve como a su propio hijo, aquel ingrato que incluso intentó pegarle.

¡Bah! Cuando él tenía nueve años [se refiere a su hijo], se corrió de una pelea. Yo lo vi. Fue tan embarazoso, que casi vomito. Le dije: "Voy a hacer de ti un hombre, así tenga que partirte en dos". E hice de él un hombre. Cuando tenía dieciséis, tuvimos una pelea. Me pegó en la mandíbula (...) era un muchacho grande. No lo veo hace dos años. Hijos (...) nos rompen el corazón. 
¿Puede una persona perturbada tomar una decisión objetiva sobre la vida, la libertad o el patrimonio de otra? Evidentemente, no. Difícil tarea, entonces, la de los juzgadores. Son personas con sentimientos, vivencias, experiencias, ideologías, frustraciones y preferencias. ¿Cómo lograr poner todo ello de lado al momento de juzgar? En definitiva, parece complicado - no creo que imposible- evitar personalizar en ocasiones el conflicto que es puesto en conocimiento de un juez; sobre todo cuando dicho conflicto está vinculado a hechos que forman parte de las vivencias personales de dicho juzgador.

Brillante es, por ello, el discurso que hace el correcto jurado n. ${ }^{\circ} 11$ a sus compañeros, luego de una de las peleas originadas en el calor de las argumentaciones:

Esta pelea (...) para eso no estamos aquí, para pelear. Tenemos una responsabilidad. Esto es lo que siempre pensé que es tan especial de la democracia (...) que nos (...) ¿cuál es la palabra? (...) "notifican" (...) que nos notifican por correo para decidir la culpabilidad o inocencia de un hombre de quien nunca antes oímos. No tenemos nada que ganar ni perder por nuestro veredicto. Ésta es una de las razones por las que somos fuertes. No deberíamos convertir esto en algo personal. Gracias.

La personalización del conflicto suele ser una tentación del inconsciente, que traiciona al propio consciente del juzgador. Vale decir, un juez puede tener la mejor disposición para actuar con corrección en la toma de sus decisiones; sin embargo, también es posible que ese propósito se vea afectado por una serie de traumas o sensibilidades que reposan en el fuero interno del individuo y adonde sólo puede llegarse vía la introspección.

La situación del jurado n. ${ }^{\circ} 10^{28}$ tiene matices de diferencia respecto a la del jurado n. ${ }^{\circ}$. Se trata de un hombre perverso e ignorante que se cree superior al joven acusado, porque no pertenece a los barrios mar-

${ }^{28}$ La actuación de Ed Begley es, sencillamente, brillante. 
ginales y porque sus rasgos son caucásicos. Sus expresiones son sumamente ofensivas y carentes de inteligencia. Es un racista, por definición.

Si tuviera que escoger cuál es la escena mejor lograda del filme, definitivamente, me quedaría con aquella en la que el jurado $n$. $^{\circ} 10$ intenta convencer de la culpabilidad del acusado al resto, basándose implícitamente en sus rasgos físicos y en su condición de pobre marginal. La indignación de sus compañeros -incluso de los que creen en la culpabilidad del acusado - es de tal magnitud, que poco a poco se van parando de la mesa y le dan la espalda mientras habla.

Saben como miente esta gente. Nacen así. No tengo que decírselos a ustedes. Esta gente no sabe lo que es la verdad. Ellos no necesitan un gran motivo para matar a alguien. No, señor; ellos se emborrachan. Son grandes bebedores, todos ellos. Ustedes lo saben (...). Así son por naturaleza. ¿Saben a qué me refiero? Violentos (...). La vida humana no significa tanto para ellos como para nosotros. Discuten y se pelean todo el tiempo; y si matan a alguien, matan a alguien. No les importa. Seguro, también tienen algunas cosas buenas. Soy el primero en decir eso. Conocí a un par que eran buenos (...) pero es la excepción. ¿Saben lo que digo? La mayoría es como si no tuvieran sentimientos. Pueden hacer de todo (...). Escúchenme: ellos no son buenos. No hay ni uno que sea bueno (...). Esta gente es peligrosa. Son salvajes.

El jurado $n .^{\circ} 10$ odia a una clase de gente y prejuzga la responsabilidad de un joven acusado que pertenece a esa clase, no necesariamente por una experiencia personal - no lo sabemos-, sino quizá por la forma en la que ha sido educado. Alega conocer muy bien a las personas que pertenecen a esa clase, y los argumentos para condenar al joven acusado están justificados por sus odios y prejuicios personales.

No olvidemos que los prejuicios que pueden afectar a cualquier ser humano $-y$, por ende, a un juzgador - tienen diversa naturaleza: racial, de origen, de clase, de sexo, de preferencia sexual, de edad, etcétera. Sin embargo, más allá de la identificación de dichos prejuicios, compete también definir cuál es el origen de ellos y en qué 
medida afectan al individuo en su responsabilidad de juzgar con rectitud..$^{29}$

La imparcialidad y objetividad son virtudes exigidas a un juez. Considero, sin embargo, que es prácticamente imposible pedirle a un ser humano que sea absolutamente objetivo en sus criterios y decisiones; de lo contrario, dejaría de ser humano y se convertiría en una máquina. ¿Quién sabe si el jurado $n{ }^{\circ} 8$ también se vio afectado por prejuicios que no fueron puestos de manifiesto en el filme y que lo llevaron a considerar que el joven acusado era inocente?

El problema, creo yo, no es el de la natural falta de objetividad para medir o calificar algunos hechos; el problema se da cuando permitimos que nuestras sensibilidades, odios y traumas personales nos dominen al momento de tomar una decisión tan importante sobre la vida, la libertad o el patrimonio de otra persona. Vale decir, nuestras decisiones siempre tendrán el aroma de nuestros pensamientos y criterios, los que a su vez se forman como consecuencia de nuestras vivencias personales. Sin embargo, permitir que esas vivencias personales y sensibilidades destruyan nuestra capacidad de razonar y de descubrir una verdad, convirtiendo la responsabilidad de dicho descubrimiento en una venganza o en la satisfacción de un odio interno, me parece perverso y mezquino.

Es claro que habrá quienes no podrán evitarlo y quizá, más allá del desprecio por su evidente perversidad y mezquindad, merezcan nuestra compasión y conduelo; no obstante, es evidente que esta clase de personas no tendrá la capacidad para asumir el rol de juzgador, en absoluto. No quiero entrar en terrenos que no son de mi especialidad, pero es sabido que descubrir a este tipo de personas es perfectamente posible con la aplicación de la psicología y el psicoanálisis; ello, por supuesto, para evitar que asuman una responsabilidad tan importante.

29 Cuando escribo sobre la posibilidad de que los prejuicios afecten al individuo en su posibilidad de "juzgar con rectitud", estoy refiriéndome al sentido más amplio de la palabra juzgar; vale decir, no solo a la toma de decisiones finales sobre la vida, la libertad o la propiedad de una persona, sino también a todas las cuestiones incidentales propias de un proceso y al trato mismo del individuo acusado o agraviado en dicho proceso. 


\section{Conclusión}

Es evidente que los conflictos legales requieren de una solución y es claro que esta dependerá de la participación de uno o más seres humanos que son comprometidos en la función jurisdiccional. El problema es que siempre existirá la posibilidad -incluso, cumplidas todas las instancias - de que la decisión que se tome no sea la correcta desde una perspectiva estrictamente de justicia. ${ }^{30}$

Por ello, con relación a la pregunta que se formuló líneas atrás, en cuanto a si el ser humano estaba preparado para juzgar correctamente, mi respuesta sería que no, en principio, pero que no queda más remedio que seguir adelante y confiar en el proceso de selección y capacitación de los juzgadores, buscando siempre neutralizar los vicios arriba referidos: falta de valentía, autoestima herida, obcecación, seducción del poder, prejuicios personales y culturales.

Sabias, por ello, son las palabras que nos dirigió Jesucristo y que fueron recogidas por san Mateo: "No juzguen para que no sean juzgados. Porque con el juicio que juzguen serán juzgados". Es evidente que el Señor se refería a la condición natural que tiene el ser humano para juzgar al resto y a los hechos que ocurren a su alrededor, siendo la recomendación la de no pervertir esa condición natural y contaminarla con nuestros odios, defectos y prejuicios. Tarea difícil, pero, repito, no imposible.

30 Las reflexiones contenidas en este artículo no se limitan, en lo absoluto, a los jueces peruanos. Por el contrario, destacando la virtud moral y profesional de muchos de ellos, es importante señalar que se trata de un análisis de los vicios que se presentan en los seres humanos en general y que, por lo tanto, pueden afectar a los que asumen la responsabilidad de tomar decisiones de carácter jurisdiccional en cualquier país. 


\section{Bibliografía}

AHRENS, Heinrich. Curso de derecho natural ó filosofía del derecho formado con arreglo al estado de esta ciencia en Alemania. Traducido y aumentado con notas y una tabla analítica de materias por orden alfabético por don Ruperto Navarro Zamorano, abogado del Ilustre Colegio de Madrid. Madrid: Boix Editor, 1841.

CARNELUTTI, Francesco. Las miserias del proceso penal. Lima: Temis, 1999.

Estudio realizado por el Departamento de Psicología de la Universidad de Yale en bebés de entre seis y diez meses de vida. Gaceta Yale-México. Primavera del 2008, volumen 3, n. ${ }^{\circ}$ 1. México, p. 5.

MERRYMAN, John Henry. La tradición jurídica romano-canónica. México D.F.: Fondo de Cultura Económica, 1997. 